\title{
Ground cover rice production systems increase soil carbon and nitrogen stocks at regional scale
}

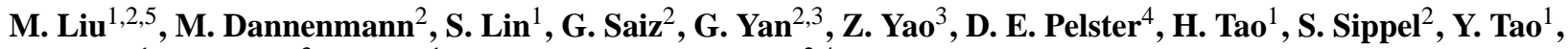 \\ Y. Zhang ${ }^{1}$, X. Zheng ${ }^{3}$, Q. Zuo ${ }^{1}$, and K. Butterbach-Bahl ${ }^{2,4}$ \\ ${ }^{1}$ College of Resource and Environmental Science, China Agricultural University, Beijing 100193, China \\ ${ }^{2}$ Institute of Meteorology and Climate Research, Atmospheric Environmental Research (IMK-IFU), Karlsruhe Institute of \\ Technology, Garmisch-Partenkirchen 82467, Germany \\ ${ }^{3}$ State Key Laboratory of Atmospheric Boundary Layer Physics and Atmospheric Chemistry (LAPC), Institute of \\ Atmospheric Physics, Chinese Academy of Sciences, Beijing 100029, China \\ ${ }^{4}$ Livestock Systems and Environment, International Livestock Research Institute, Nairobi 30709-00100, Kenya \\ ${ }^{5}$ College of Resource and Environmental Science, Yunnan Agricultural University, Kunming 650201, China
}

Correspondence to: S. Lin (linshan@cau.edu.cn)

Received: 4 January 2015 - Published in Biogeosciences Discuss.: 27 February 2015

Revised: 16 July 2015 - Accepted: 25 July 2015 - Published: 14 August 2015

\begin{abstract}
Rice production is increasingly limited by water scarcity. Covering paddy rice soils with films (so-called ground cover rice production system: GCRPS) can significantly reduce water demand as well as overcome temperature limitations at the beginning of the growing season, which results in greater grain yields in relatively cold regions and also in those suffering from seasonal water shortages. However, it has been speculated that both increased soil aeration and temperature under GCRPS result in lower soil organic carbon and nitrogen stocks. Here we report on a regional-scale experiment conducted in Shiyan, a typical rice-producing mountainous area of China. We sampled paired adjacent paddy and GCRPS fields at 49 representative sites. Measured parameters included soil carbon $(\mathrm{C})$ and nitrogen $(\mathrm{N})$ stocks (to $1 \mathrm{~m}$ depth), soil physical and chemical properties, $\delta^{15} \mathrm{~N}$ composition of plants and soils, potential $\mathrm{C}$ mineralization rates, and soil organic carbon (SOC) fractions at all sampling sites. Root biomass was also quantified at one intensively monitored site.

The study showed that: (1) GCRPS increased SOC and $\mathrm{N}$ stocks 5-20 years following conversion from traditional paddy systems; (2) there were no differences between GCRPS and paddy systems in soil physical and chemical properties for the various soil depths, with the exception of soil bulk density; (3) GCRPS increased above-ground and root biomass in all soil layers down to a $40 \mathrm{~cm}$ depth; (4)
\end{abstract}

$\delta^{15} \mathrm{~N}$ values were lower in soils and plant leaves indicating lower $\mathrm{NH}_{3}$ volatilization losses from GCRPS than in paddy systems; and (5) GCRPS had lower C mineralization potential than that observed in paddy systems over a 200-day incubation period. Our results suggest that GCRPS is an innovative production technique that not only increases rice yields using less irrigation water, but that it also increases SOC and $\mathrm{N}$ stocks.

\section{Introduction}

Globally, more than 3 billion people depend on rice as a staple food (FAO, 2011). Water used for irrigation is becoming increasingly scarce due to growing water demands from increasing populations and economies across Asia and from projected climatic changes. It is expected that by 2025 about 15 million ha of irrigated rice, 27 million ha of rainfed rice, and nearly 20 million ha of rainfed upland rice will suffer from water scarcity worldwide (Bouman, 2007). An annual increase of about $8-10$ million tons will be required to meet the global forecasted needs over the next 20 years (IRRI, 2011). In this scenario, water-saving technologies are urgently needed to cope with such rice production demands.

China is the world's largest rice producer with an average rice production rate of 197 million tons $\mathrm{yr}^{-1}$, which in 
2009 was grown on ca. 30 million hectares and accounted for $43.7 \%$ of the total national cereal grain production (Fan et al., 2010). Water shortages already affect more than 4 million ha devoted to rice production in China, and a significant proportion of this area also shows comparatively low yields resulted from low-temperature limitations. One of the most promising techniques to overcome these limitations is the ground cover rice production system (GCRPS). Here, the soil is covered - typically with plastic film - to reduce evaporation, seepage losses and increase springtime soil temperatures. The soil is kept moist between irrigation periods thanks to the covering material, which reduces irrigation water demand by $50-90 \%$ (Tao et al., 2015). The actual reduction in irrigation water demand is dependent on soil type, precipitation, and cultivation duration (Tao et al., 2006; Liu et al., 2003). Furthermore, high-yielding lowland rice varieties (middle-duration cultivar, about 140 days) can still be grown in upland locations using GCRPS, which results in similar or even greater yields than paddy systems (Qu et al., 2012; Liu et al., 2013, 2014; Tao et al., 2015). Thus, GCRPS is consistent with China's 12th Five Year Plan that requires development of technologies to reduce the water demand and greenhouse gas emissions (GHG) in agricultural production (Yao et al., 2014; Tao et al., 2015).

Improving rice production systems should not be solely focused on increasing productivity, but should also consider other aspects affecting sustainability, such as preservation of optimal levels of soil organic carbon (SOC) and total N. Soil organic matter (SOM) helps to maintain soil structure and fertility, decreases the risk of soil erosion and degradation (Watts et al., 2006; Powlson et al., 2011), provides nutrients to plants and soil microbes (Tiessen et al., 1994), and increases soil water holding capacity, thereby improving the systems' ability to resist drought stress (Rawls et al., 2003). The sustainability of a production system tends to be correlated with the maintenance or increase of SOM stocks, which tends to lead to increased yield potentials worldwide (Lehmann et al., 2007). The amount of organic C stored in a soil is a fine balance between organic $\mathrm{C}$ inputs, mineralization, and lateral exports (Jenny, 1941; Amundson, 2001). These processes are strongly affected by temperature, water available to plants, soil mineral composition, and the chemical properties of the precursor biomass (Swift, 2001; Saiz et al., 2012).

Compared to upland cereal production systems, submerged paddy rice cultivation is considered to be a sustainable cropping system because the permanent presence of water results in anoxic conditions that drive soil redox potential to the lowest natural levels (Gao et al., 2008; Pan et al., 2010). It is widely acknowledged that decomposition of SOM is slower in submerged soils than in aerated soils (Sahrawat, 2004), and previous studies have shown that continuous rice cropping on submerged soils may favor the maintenance, and even the increase of SOM stocks (Cassman et al., 1995; Bronson et al., 1997; Witt et al., 2000). Consequently, it has been hypothesized that the absence of permanently anaerobic conditions, in conjunction with increased soil temperatures under GCRPS cultivation may result in either unchanged or increased SOC losses as a result of potentially enhanced microbial decomposition (Pan et al., 2003, 2010; Qu et al., 2012). Indeed, earlier studies showed trends towards lower SOC and total $\mathrm{N}$ stocks in fields using the plastic film-based GCRPS technique. However, these studies only investigated the topsoil $(0-20 \mathrm{~cm})$ above the hardpan at a single experimental site (Li et al., 2007; Fan et al., 2012; Qu et al., 2012). The GCRPS-induced shift from flooded soils to higher aeration and soil temperatures at the start of the growing season may result in reduced $\mathrm{CH}_{4}$ emissions, while $\mathrm{N}_{2} \mathrm{O}$ emissions (Kreye et al., 2007; Yao et al., 2014) and C mineralization rates may increase (Koch et al., 2007). On the other hand, high ammonia volatilization in paddy systems tends to result in low $\mathrm{N}$ use efficiency (approx. 30\%) (Ju et al., 2009) and covering the soil surface might reduce ammonia volatilization rates, increase fertilizer use efficiency, plant biomass and/or soil $\mathrm{N}$ stocks. Furthermore, variable soil water regimes such as that observed under GCRPS cultivation can increase root biomass (Thakur et al., 2011; Uga et al., 2013), which in turn could promote $C$ inputs into the soil. A thorough regional-scale evaluation of GCRPS effects on SOC and total $\mathrm{N}$ stocks is needed to address these effects, but has not yet been reported.

To evaluate the impact of GCRPS on soil C and N stocks as well as identifying the primary $\mathrm{N}$ loss pathways from GCRPS and paddy systems using the natural abundances of ${ }^{15} \mathrm{~N}$, we conducted a field study sampling 49 pairs of neighboring GCRPS and paddy fields in the Shiyan region, central China, where the GCRPS technique was first introduced approximately 20 years ago. We hypothesized that decreased soil moisture conditions and increased soil temperature and redox potential in GCRPS would stimulate soil $\mathrm{C}$ and $\mathrm{N}$ mineralization, leading to an overall reduction of soil $\mathrm{C}$ and $\mathrm{N}$ stocks under GCRPS at a regional scale.

\section{Materials and methods}

\subsection{Sampling region characteristics}

The study was situated in the Shiyan region, Hubei province, central China $\left(32^{\circ} 02^{\prime}\right.$ to $33^{\circ} 10^{\prime} \mathrm{N}, 109^{\circ} 44^{\prime}$ to $111^{\circ} 04^{\prime} \mathrm{E}$; $169 \mathrm{~m}$ to $661 \mathrm{~m}$ a.s.l.; see Supplement Table S1), where GCRPS was introduced at the end of the last century (Shen et al., 1997; Liang et al., 1999). Shiyan is located in the QinBaShan Mountains with peaks reaching a maximum altitude of $2740 \mathrm{~m}$ a.s.l. The area is in the northern subtropical agro-climatic zone of China's eastern monsoon region (Smit and Cai, 1996). Low temperatures at the start of the growing season together with severe seasonal water scarcity often limit rice production in these mountainous regions (Shen et al., 1997). The mean annual temperature and rainfall (cal- 
culated for the 1961-2009 period from seven meteorological stations located in the respective counties of Shiyan) are $15.3^{\circ} \mathrm{C}$ and $829 \mathrm{~mm}$, respectively (Zhu et al., 2010). There is little inter-annual variation in temperature and rainfall (coefficient of variations of 0.01 and 0.05 ). Annual rainfall patterns show pronounced seasonality, with approximately $45 \%$ $(375 \mathrm{~mm})$ of the rainfall occurring during the summer period (June to August). The mean total sunshine hours per year is $1835 \mathrm{~h}$ (Zhu et al., 2010). Traditional lowland rice cultivation (paddy) and GCRPS are spatially interwoven, because only some farmers adopted GCRPS after its invention 2 decades ago. This limited adoption is due to the implications GCRPS cultivation has on farming activities, labor demand, and associated costs (Zhou et al., 2008). In most cases the adoption of GCRPS by individual farmers was documented by the local administration so it was possible to trace specific land management records for the selected sites and fields.

\subsection{Site and field selection}

Site selection was performed by experienced staff members from the Department of Agriculture in Shiyan and extension personnel who have been working closely with farmers at the individual local villages. Specific attention was paid to ensure proper representativeness of the different ricegrowing areas (i.e., varying altitudes, contrasting soil types, and proper coverage of the range of time since adoption of GCRPS). Information on fertilizer use, and soil and crop management was obtained through farmer interviews (Table S2). Topdressing is not used in GCRPS since the plastic film covers the soil surface; rather the farmers usually broadcast all the fertilizer before transplanting (Liu et al., 2013). The day before transplanting, a compound NPK fertilizer and urea were applied to the soil surface in a single dose and incorporated into the soil by ploughing. The total $\mathrm{N}$ input was about $150 \mathrm{~kg} \mathrm{Nha}^{-1}$ for GCRPS. The soil surface was then leveled and covered with a transparent film $5 \mu \mathrm{m}$ thick (Liu et al., 2013). For paddy systems, an average of $100 \mathrm{~kg} \mathrm{~N} \mathrm{ha}^{-1}$ was applied as a compound NPK fertilizer to the soil surface and incorporated to a depth of $20 \mathrm{~cm}$ before transplanting. At tillering and grain filling stages, additional doses of $40 \mathrm{~kg} \mathrm{Nha}^{-1}$ were given as urea in order to increase ricemilling quality, protein content (Wopereis-Pura et al., 2002; Leesawatwong et al., 2005), and yield. This resulted in a total $\mathrm{N}$ application rate of approximately $180 \mathrm{~kg} \mathrm{~N} \mathrm{ha}^{-1}$ for the paddy rice system.

We compared, across a region of $5000 \mathrm{~km}^{2}, 49$ pairs of neighboring fields that were managed either as traditional paddy rice fields or where GCRPS had been applied continuously for 5-20 years. A total of 49 sites with paired treatments consisting of GCRPS vs permanent flooding paddy fields were selected for soil and plant sampling. Regardless of the current production system, all sites had been growing rice for more than 40 years. The distance between the paired plots was less than $100 \mathrm{~m}$ in most cases, with only 9 out of
49 paired plots being more than $250 \mathrm{~m}$ apart (Table S1). Geographical coordinates of the sites and fields were recorded by GPS (Garmin Colorado 300) and altitudes were obtained using the global digital elevation model (GDEM) provided by NASA and METI (2008).

\subsection{Sampling methodology and analytical procedure}

Soil samples from the 49 paired sites were collected before field preparation during March and April 2011. These sites represented a wide range of different soil types (Table S1). At each of the 98 fields, six to nine spatial replicates were taken with the aid of a soil corer $(3.5 \mathrm{~cm}$ diameter) at four depths intervals $(0-20,20-40,40-60$, and $70-90 \mathrm{~cm})$. Additionally, three replicate samples were collected from each soil profile excavated in each field for each depth and analyzed for bulk density (Blake and Hartge, 1986) and soil texture (Gee, 1986).

Soil samples for each depth interval were air-dried for 5 days and sieved to $2 \mathrm{~mm}$. Identifiable plant material (>2 mm) was removed during sieving. Soil pH (Mc Lean, 1982) was measured in a $1: 2.5$ soil-water solution using a combined electrode $\mathrm{pH}$ meter (HI 98121, Hanna Instruments, Kehl am Rhein, Germany). Extractable soil $\mathrm{NO}_{3}^{-}-\mathrm{N}$ and $\mathrm{NH}_{4}^{+}-\mathrm{N}$ (Keeney and Nelson, 1982) was estimated from $1: 10$ soil$\mathrm{CaCl}_{2}(0.01 \mathrm{M})$ extracts using an AutoAnalyzer (AA3, Bran $\&$ Luebbe, Nordstadt, Germany). Sub-samples for the determination of soil $\mathrm{C}$ and $\mathrm{N}$ concentration and ${ }^{15} \mathrm{~N}$ isotope natural abundance were powdered in a ball mill (MM200, Retsch, Haan, Germany) with the soil carbonates removed prior to C analyses (Harris et al., 2001; Walthert et al., 2010). Analyses were conducted using a Costech elemental analyzer (Costech International S.p.A., Milan, Italy) fitted with a Zero Blank autosampler coupled via a ConFloIII to a Thermo Finnigan Delta V Plus isotope ratio mass spectrometer (Thermo Scientific, Waltham, MA, USA). Soil C and N stocks were calculated using element concentrations and bulk density data for all sites.

Leaves at maximum tillering stage and aboveground plant biomass at maturity stage were sampled from 36 paired sites (at some sites rice was not planted as foreseen, due to a severe drought) with three replicates from each site used for analysis of ${ }^{15} \mathrm{~N}$ natural abundance using a $\mathrm{CN}$ analyzer coupled to a mass spectrometer (see above). Carbon and $\mathrm{N}$ concentrations were then determined by an elemental analyzer (EA1108). Carbon and $\mathrm{N}$ assimilated in aboveground biomass were calculated as the sum of grain and straw dry matter multiplied by grain and straw $\mathrm{C}$ or $\mathrm{N}$ concentration at harvest.

Root biomass was quantified at a long-term experimental site in Fang County $\left(32^{\circ} 07^{\prime} \mathrm{N}, 110^{\circ} 43^{\prime}\right.$ E; Fig. S1 in the Supplement; Tao et al., 2015) where 22 paired GCRPS and paddy sites were located (Table S1). The site consists of the two production systems (paddy and GCRPS) and two $\mathrm{N}$ fertilizer application rates $\left(0,150 \mathrm{~kg} \mathrm{~N} \mathrm{ha}^{-1}\right)$ in three-fold replication. All 12 subplots $(8.5 \mathrm{~m} \times 9.5 \mathrm{~m})$ were arranged in a com- 
pletely randomized block design. Root biomass was quantified for three replicate cores in each of the subplots. For this purpose, soil columns ( $40 \mathrm{~cm}$ height and $15 \mathrm{~cm}$ diameter) were collected at the maximum tillering stage using stainless steel cylinders. The soil column was separated into depth intervals of $0-10,10-20$, and $20-40 \mathrm{~cm}$. Soil samples were placed in mesh bags and set in a water stream to remove soil particles and then cleaned by tap water on a $0.2 \mathrm{~mm}$ mesh. Cleaned root samples in different soil depths were transferred into small envelopes and oven-dried at $75^{\circ} \mathrm{C}$ for $24 \mathrm{~h}$.

Potential soil $\mathrm{C}$ mineralization rates from all 49 paired paddy and GCRPS sites were determined using a laboratory incubation assay. Three soil samples with a volume of $20 \mathrm{~cm} \times 10 \mathrm{~cm} \times 20 \mathrm{~cm}$ (depth) were sampled at each site using a spade. Samples were composited and air-dried. Three replicates with $30 \mathrm{~g}$ of soils were incubated for 200 days at $25^{\circ} \mathrm{C}$ at $60 \%$ soil water-holding capacity in $150 \mathrm{~mL}$ bottles. $\mathrm{CO}_{2}$ fluxes were measured daily for the first 10 days, then every 3 days for the following 3 weeks and then every 1-2 weeks afterwards. The gas measurement period was from $5 \mathrm{~min}$ to $4 \mathrm{~h}$ depending on $\mathrm{CO}_{2}$ flux rates. For flux measurements, the jars were closed gas-tight and $\mathrm{CO}_{2}$ headspace concentrations were measured with a non-dispersive infrared sensor (Premier, Dynament, United Kingdom) at $10 \mathrm{~s}$ intervals. $\mathrm{CO}_{2}$ fluxes were calculated from concentration changes with time, considering headspace volume, temperature, and air pressure. Total cumulative emissions were obtained by summing the measured daily fluxes using trapezoidal integration assuming a linear change in flux between measurements.

Organic matter $(\mathrm{OM})$ fractions were physically separated before and after incubation using a slightly modified procedure to that described in Zimmermann et al. (2007). Briefly, $30 \mathrm{~g}$ of dried soil $(<2 \mathrm{~mm})$ were added to $161 \mathrm{~mL}$ water and dispersed by means of a calibrated ultrasonic probe (Labsonic 2000, B Braun, Melsungen, Germany) using a light output energy $\left(22 \mathrm{~J} \mathrm{ml}^{-1}\right)$. The dispersed suspension was then wet sieved over a $53 \mu \mathrm{m}$ mesh size until clear rinsing water was achieved. The fraction $>53 \mu \mathrm{m}$ was dried at $40^{\circ} \mathrm{C}$ and weighed. This fraction contained sand-size particles and aggregates (heavy fraction; HF), as well as particulate organic matter (light fraction; LF). These two fractions were separated using the procedure for recovery of organic matter from soils using static dense media as described in Wurster et al. (2010). The dried fraction $>53 \mu \mathrm{m}$ was stirred in a water/sodium polytungstate solution with a density of $1.87 \mathrm{~g} \mathrm{~cm}^{-3}$. The mixture was centrifuged at $1000 \mathrm{~g}$ for 15 min, and allowed to settle overnight prior to freezing. The LF was subsequently decanted and both fractions were then washed with deionized water, dried at $40^{\circ} \mathrm{C}$, and weighed. The solution $<53 \mu \mathrm{m}$ (silt and clay) was filtered through a $0.45 \mu \mathrm{m}$ membrane filter and the material retained in the membrane $(\mathrm{s}+\mathrm{c})$ was then dried at $40^{\circ} \mathrm{C}$ and weighed. An aliquot of the filtrate was frozen to determine the amount of dissolved organic carbon (DOC) using a $\mathrm{C} / \mathrm{N}$ liquid analyzer (Multi N/C ${ }^{\circledR} 3100$ Analytik Jena, Jena, Germany).

\subsection{Statistical analyses}

All statistical analysis and calculations were performed in the Statistics Analysis System (SAS, version 8.2). ShapiroWilk tests were applied to check for normal distribution. Non-parametric tests were applied if the data were not normally distributed. Before any statistical test was performed, we tested for significant differences between GCRPS and paddy sites according to a model that included soil type, years since conversion, soil type, and elevation as potential variables influencing the percentage change of SOC / N stocks between both systems. However, we found that the percentage change of SOC/N stocks was not significantly affected by soil type, years since conversion, elevation, nor by any of the interactions. Therefore, we pooled over different soil types, years since conversion, and elevation in the subsequent statistical analysis (Table S3). A paired $t$ test was used to test for differences in soil texture (clay, silt, and sand content), bulk density, $\mathrm{pH}$, and mineral $\mathrm{N}$ concentrations (Nmin) between GCRPS and paddy sites. All statistical analyses and calculations were performed using parametric (paired and two-tailed t-test, Pearson chi-square) and non-parametric (Wilcoxon matched pairs rank sum test; twotailed) tests. Differences in root biomass between the two systems were tested using a general linear model (GLM) procedure. Results are expressed as arithmetic means \pm standard error of the means. Levels of significance at $0.001,0.01$, and 0.05 probability were used, denoted by $* * *, * *$, and $*$, respectively. Results which were not significant were denoted by $n s$.

\section{Results}

Average SOC concentrations and stocks were higher in GCRPS than in paddy sites for each soil depth interval except for the top layer $(0-20 \mathrm{~cm}$; Fig. 1a, c; see Table S4 for details). Similarly, total $\mathrm{N}$ concentrations and stocks over the $1 \mathrm{~m}$ profile also tended to be larger in GCRPS than in paddy sites, although significant differences were only observed in the $20-40 \mathrm{~cm}$ depth interval (Fig. 1b, d; Table S4). There were no detectable differences in soil texture (Fig. 2a, b, c; Table S4), pH, or mineral $\mathrm{N}$ content (Fig. 2e, f; Table S4) between GCRPS and paddy sites for any soil depth interval. Soil bulk density (Fig. 2d; Table S4) tended to be lower in GCRPS than in paddy sites over the $1 \mathrm{~m}$ soil profile, although significant differences were only found in the $20-40 \mathrm{~cm}$ depth interval $(P<0.0001)$.

Mean $\mathrm{C}$ and $\mathrm{N}$ assimilation rates in aboveground biomass at maturity were higher in GCRPS than in paddy sites (Fig. 3; $P<0.0001,=0.0002$ for $\mathrm{C}$ and $\mathrm{N}$ ). Root biomass from the one selected site was significantly affected by the production 


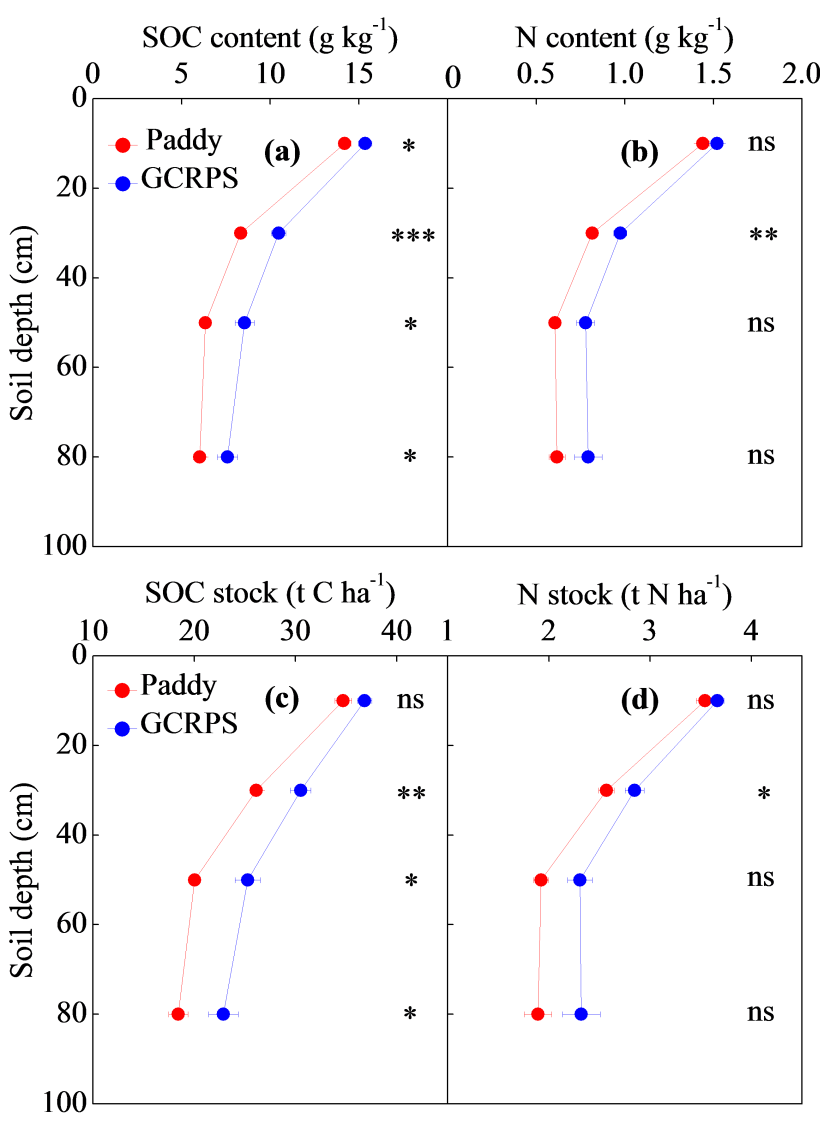

Figure 1. Concentrations and stocks of soil organic carbon and total nitrogen in traditional paddy fields and GCRPS at different soil depths. Data presented are the mean values pooled over 49 paired sites (for 0-20 and 20-40 cm, $n$ is 147; for $40-60 \mathrm{~cm}, n$ is 108 ; and for $70-90 \mathrm{~cm}, n$ is 63 ). Errors bars indicate the standard error of the means. $* * *, * *$, and $*$ denote significance at $0.001,0.01$, and 0.05 probability levels, respectively. Values that are not significant are denoted by $n s$.

system, but not by $\mathrm{N}$ fertilizer rates or by the interaction of the production system and $\mathrm{N}$ fertilization (Fig. 4; Table S4). Pooled over the two $\mathrm{N}$ fertilizer rates, the root biomass at maximum tillering stage was significantly greater in GCRPS than in paddy sites for all depth intervals down to $40 \mathrm{~cm}$ depth (Fig. 4).

Potential $\mathrm{C}$ mineralization rates did not differ between GCRPS and paddy sites (data not shown), although paddy soils showed a tendency towards higher cumulative C loss compared to GCRPS over the 200-day incubation period (Fig. 5). For the GCRPS, the SOC contents of the various fractions were similar before and after the incubation experiment (Fig. 6). However for the paddy treatment, the amount of SOC in the heavy fraction was significantly lower after incubation compared to before the incubation $(P<0.05)$. No differences were found in the $\mathrm{s}+\mathrm{c}, \mathrm{LF}$, and DOC fractions before and after the incubation (Fig. 6).

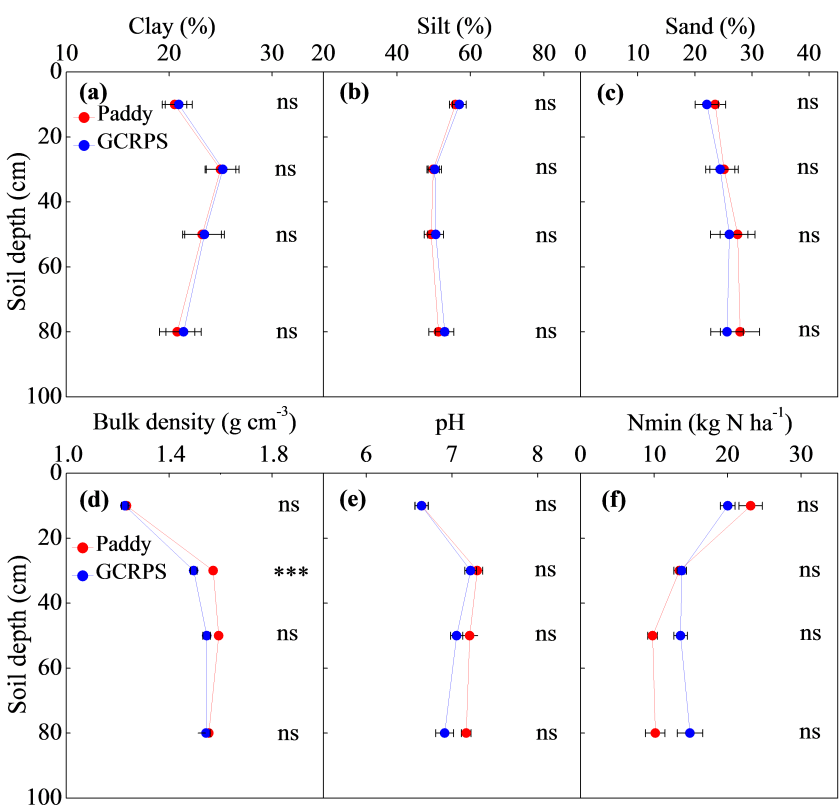

Figure 2. Average soil clay, silt, and sand contents (for 0-20 and $20-40 \mathrm{~cm}, n$ is 49 ; for $40-60 \mathrm{~cm}, n$ is 36 ; and for $70-90 \mathrm{~cm}, n$ is 21 ), soil bulk density, $\mathrm{pH}$, and mineral nitrogen concentrations $\left(\mathrm{N}_{\min }\right.$; for $0-20$ and $20-40 \mathrm{~cm}, n$ is 147 ; for $40-60 \mathrm{~cm}, n$ is 108 ; and for 70 $90 \mathrm{~cm}, n$ is 63) at different soil depths from 49 paired sites cultivated either under traditional paddy fields or GCRPS. Errors bars indicate SEM (standard error of the mean) and $* * *$ denotes significance at a 0.001 probability level. Values that are not significant are denoted by $n s$.
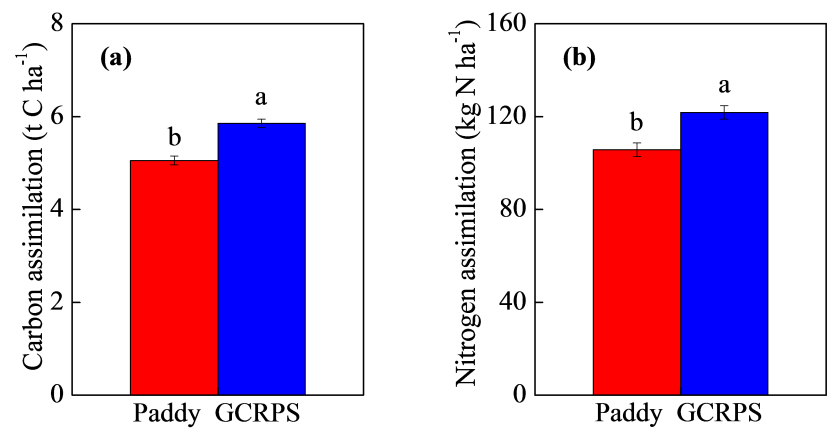

Figure 3. Carbon and nitrogen assimilated in aboveground biomass at maturity ( $n$ is 108). Data presented are the means pooled over 36 paired sites (these represent all the sites where rice was grown in 2011) with three replicates at each site. Errors bars indicate SEM. Bars labeled with different lowercase letters indicate statistically significant differences $(P<0.05)$ between paddy sites and GCRPS.

Mean soil $\delta^{15} \mathrm{~N}$ signatures were lower in GCRPS than in paddy sites at each depth interval (Fig. 7a; Table S4). The average $\delta^{15} \mathrm{~N}$ signature in plant leaves was also lower $(P<0.0001)$ in GCRPS compared to paddy fields at maximum tillering stage (Fig. 7b). Ln-transformed soil $\mathrm{N}$ concen- 


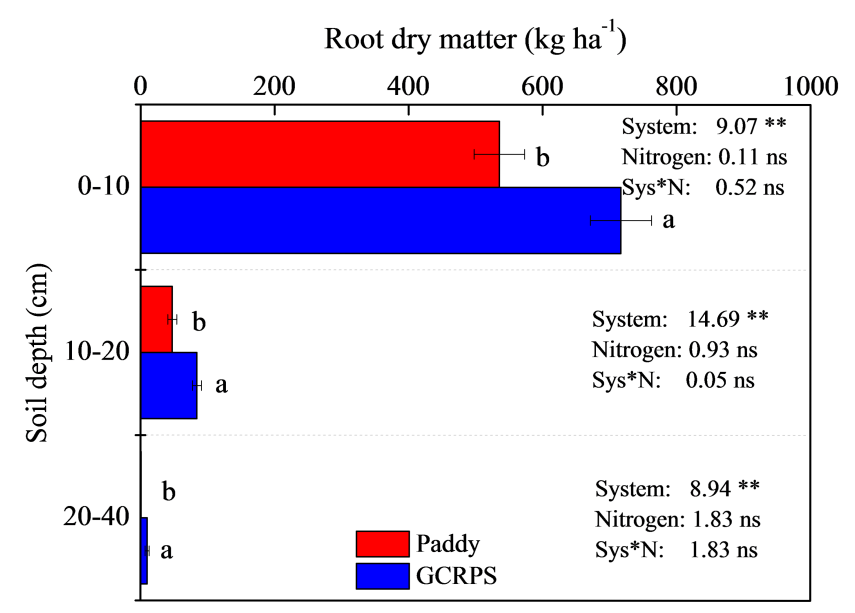

Figure 4. Root dry matter at maximum tillering stage for different soil depths in traditional paddy fields and GCRPS. $n$ is 18 and error bars denote SEM. Bars labeled with different lowercase letters indicate differences $(P<0.05)$ between paddy sites and GCRPS.

trations were inversely correlated with corresponding $\delta^{15} \mathrm{~N}$ values in either GCRPS or paddy sites (Fig. 8).

\section{Discussion}

Here, we provide a thorough regional-scale evaluation of GCRPS effects on SOC and total N stocks, based on sampling of cultivated fields at 49 paired sites (i.e., adjacent sites experiencing comparable soil and environmental conditions, Figs. 2 and S1 and Tables S1 and S4) down to $1 \mathrm{~m}$ depth across an entire geographical region. Our results show that within the sampling region, conversion of paddy fields to GCRPS increased SOC concentrations (Fig. 1a; Table S4) and storage (Fig. 1c; Table S4) after 5 years since the time of conversion. We were able to identify two main processes that contributed to the positive effect of GCRPS on SOC stocks.

(a) Increased above- and belowground carbon inputs.

Plant residues and organic fertilizers directly affect the amount and quality of organic matter above the hardpan (between 20 and $40 \mathrm{~cm}$ ), while the accumulation and stabilization of subsoil OM in these agricultural systems derives mainly from dissolved OM leached from the plough layer (Tanji et al., 2003). In our study we observed larger aboveground biomass and grain yields for GCRPS compared to traditional paddy fields (Fig. 3; Liu et al., 2013). Furthermore, root biomass was also found to be greater under GCRPS cultivation in all soil layers down to $40 \mathrm{~cm}$ depth (Fig. 4; Table S4).

Recent literature has confirmed that rice cultivation under variable soil water regimes such as GCRPS results both in higher root biomass (Thakur et al., 2011; Uga et al., 2013), and more rhizodeposits (Tian et al., 2013) compared to traditional flooded paddy fields, likely because the larger above-

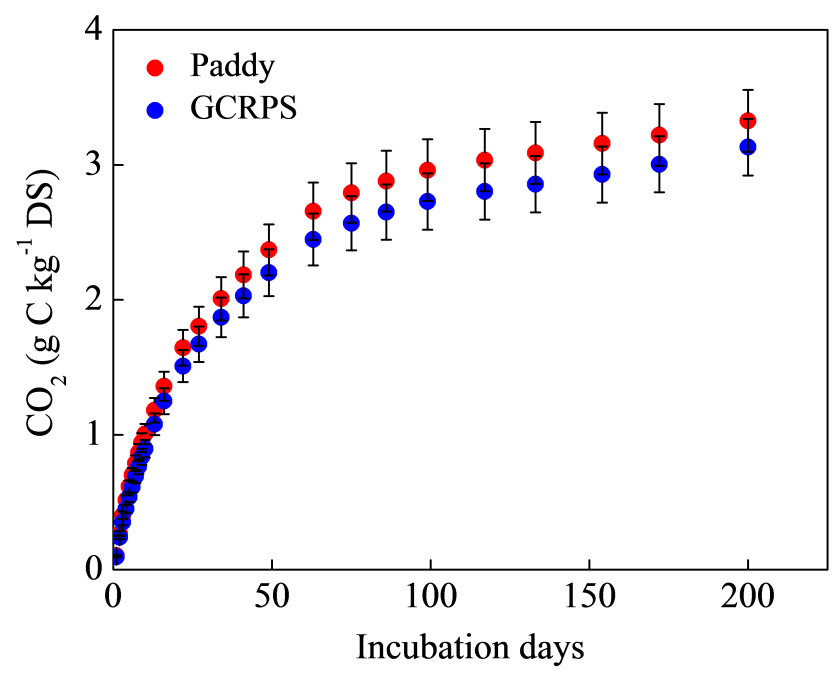

Figure 5. Differences in cumulative organic carbon mineralization during a 200-day incubation period of top soils $(0-20 \mathrm{~cm})$ collected from either paddy sites or GCRPS. Data presented are the mean values pooled over 49 paired sites. Error bars indicate SEM.

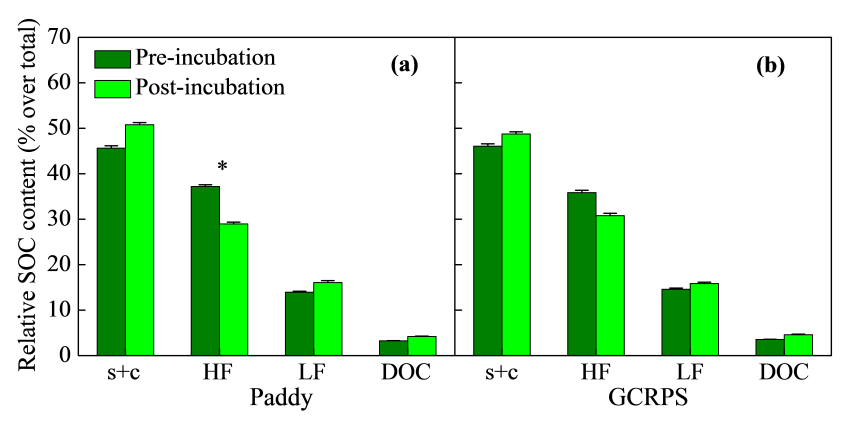

Figure 6. Relative SOC fractionation (\% of total) of topsoils (0$20 \mathrm{~cm}$ ) from either paddy sites or GCRPS-grown rice fields for the different physically separated fractions before and after a 200day incubation period. $\mathrm{s}+\mathrm{c}$ is fraction $<53 \mu \mathrm{m}$, HF/LF represent heavy/light fraction $>53 \mu \mathrm{m}$, and DOC represents dissolved organic carbon $<0.45 \mu \mathrm{m}$. For GCRPS, $n$ is 18 and for paddy sites, $n$ is 18 (random selection of 18 out of 49 paired sites). Error bars denote SEM. The asterisk indicates significant differences between preand post-incubation $(P<0.05)$.

ground biomass and grain yields require a larger root system to absorb more nutrients from the soil (Liu et al., 2003). GCRPS also promotes increased soil $\mathrm{NO}_{3}^{-}$concentrations that can lead to more balanced plant $\mathrm{N}$ nutrition $\left(\mathrm{NO}_{3}^{-}\right.$and $\mathrm{NH}_{4}^{+}$), which is beneficial for crop growth (Nacry et al., 2013). Moreover, the fluctuating soil water content inherent to GCRPS, which varies between 80 and $90 \%$ water holding capacity (WHC), can limit the accessibility to some micronutrients (e.g., $\mathrm{Mn}, \mathrm{Fe}$ ) in the topsoil if they are oxidized to forms that cannot be directly assimilated by the plant (Tao et al., 2007; Kreye et al., 2009). For example, the lack of standing water may cause increased soil aeration, and thus, 

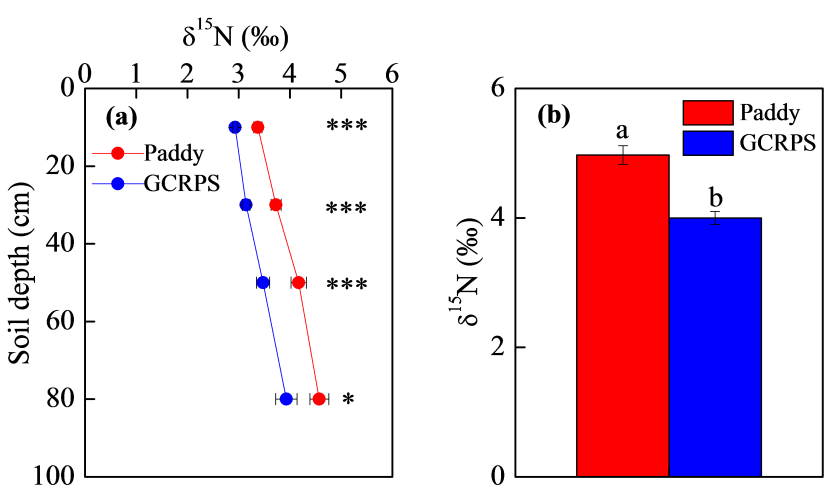

Figure 7. (a) Soil $\delta^{15} \mathrm{~N}$ isotopic signature in traditional paddy fields and GCRPS at different soil depths. Data presented are the mean values pooled over 49 paired sites (for $0-20$ and $20-40 \mathrm{~cm}, n$ is 147; for $40-60 \mathrm{~cm}, n$ is 108 ; and for $70-90 \mathrm{~cm}, n$ is 63 ). (b) $\delta^{15} \mathrm{~N}$ signature in plant leaves at maximum tillering stage. Data presented are the means pooled over 36 paired sites (these represent all the sites where rice was grown in 2011) with three replicates at each site; $n$ is 108 . Errors bars indicate the SEM. $* * *, * *$, and $*$ denote significance at $0.001,0.01$, and 0.05 probability levels, respectively. Values that are not significant are denoted by $n s$. Bars labeled with different lowercase letters indicate differences $(P<0.05)$ between paddy fields and GCRPS.

higher redox potentials (Tao et al., 2007), resulting in the oxidized form of $\mathrm{Mn}$ that greatly lowers its availability to the plant (Norvell, 1988). Therefore, rice plants in GCRPS need to develop stronger root systems capable of accessing deeper soil layers to obtain a balanced micro-nutrient supply. Even if just a few fine roots penetrate the hardpan they may represent a large difference in deep SOC storage, as root channels may further promote percolation of organic compounds into the subsoil.

(b) Greater physical protection of soil organic matter against microbial degradation.

We conducted soil incubations under controlled environmental conditions using soils from all field sites to test whether GCRPS would enhance SOM stabilization or increase C mineralization, promoting net losses of SOM (Xiong et al., 2014). Our results showed no significant differences in mineralization rates between soils from the GCRPS and paddy systems for all measuring dates over a 200-day incubation, although cumulative $\mathrm{C}$ losses over the entire incubation period were consistently greater for paddy soils (Fig. 5). This could suggest that SOM in fields managed under GCRPS may be more effectively preserved than SOM in traditional paddy systems. Besides the physicochemical protection offered by clay minerals (Koegel-Knabner et al., 2010; Saiz et al., 2012), other stabilizing mechanisms could be conferred through higher OM inputs resultant from enhanced above and belowground biomass production, as higher OM input rates are known to promote stable micro- and mesoaggregates (Six et al., 2004). However, we did not observe sig-

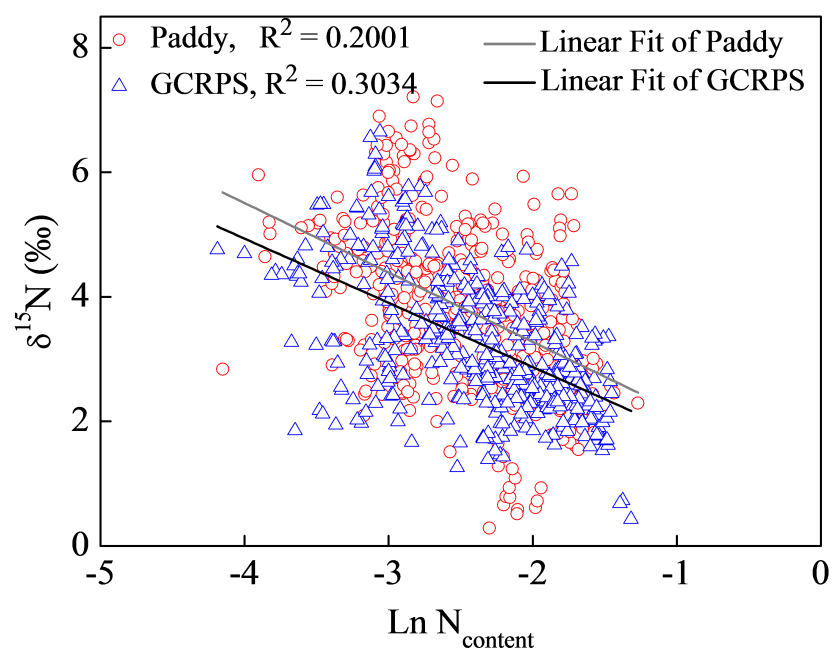

Figure 8. Correlation of $\delta^{15} \mathrm{~N}$ with Ln-transformed soil total nitrogen content up to $1 \mathrm{~m}$ depth. Data presented are all the individual samples measured across the 49 paired sites, which consist of three replicates for each site ( $n$ is 465).

nificant differences between both systems in the physically protected fractions for the topmost soil layer (Fig. 6). It is likely though, that aggregation and/or stabilization might become more relevant at deeper locations where the differences in SOC concentrations were greater. Indeed, the strong anaerobiosis and stabilization conditions prevailing at greater depths would likely promote $\mathrm{OM}$ accumulation below the hardpan, as we found in our study (Fig. 1; Koegel-Knabner et al., 2010). Also relevant within this context is the contrasting soil redox conditions observed between the two systems (Liu et al., 2013). The more frequent oscillation in redox conditions (aerobic to anaerobic and back) in GCRPS may have a strong positive influence on the generation of organo-mineral complexes, which are of paramount importance for the stabilization of OM in paddy soils (Koegel-Knabner et al., 2010).

Similar to SOC concentrations and stocks, soil organic $\mathrm{N}$ concentrations and stocks were larger in GCRPS than in paddy fields over the $1 \mathrm{~m}$ soil profile. However, significant differences were only observed in the $20-40 \mathrm{~cm}$ depth interval (Fig. 1b, d). In addition, we observed $\delta^{15} \mathrm{~N}$ enrichment in paddy soils for all soil depths (Fig. 7a), which was also reflected in the plant biomass (Fig. 7b). Bulk soil $\delta^{15} \mathrm{~N}$ is a combined signal for organic and mineral $\mathrm{N}$ compounds and may be affected by (1) the amount and isotopic signature of applied fertilizer (Yun et al., 2011), (2) isotopic fractionation occurring during $\mathrm{N}$ cycle processes, such as $\mathrm{N}$ mineralization, nitrification, and assimilation (Bedard-Haughn et al., 2003), and (3) ${ }^{15} \mathrm{~N}$ depletion of gaseous $\mathrm{N}$ compounds produced during denitrification and ammonia volatilization with subsequent ${ }^{15} \mathrm{~N}$ enrichment of the remaining soil $\mathrm{N}$ (Bedard-Haughn et al., 2003). Based on farmers' interviews, the dominant fertilizer used was a compound NPK fertilizer with urea as the $\mathrm{N}$ form $\left(\delta^{15} \mathrm{~N}\right.$ of ca. $0.5 \%$ ) (Yun et al., 
2011). As well as urea-N, 11 of the 98 sites received manure $\left(\delta^{15} \mathrm{~N}>10 \%\right)$. Most crucially, $\mathrm{N}$ fertilization rates were comparable for both management systems (GCRPS: approx. $150 \mathrm{~kg} \mathrm{Nha}^{-1}$; paddy soils: approx. $\left.180 \mathrm{~kg} \mathrm{Nha}^{-1}\right)$. Therefore, kinetic isotope fractionation processes in the soil rather than mixing of different $\mathrm{N}$ sources with distinct $\delta^{15} \mathrm{~N}$ signatures likely account for the observed differences in soil $\delta^{15} \mathrm{~N}$. This is confirmed by the observation that Ln-transformed soil $\mathrm{N}$ concentrations were inversely correlated with the $\delta^{15} \mathrm{~N}$ values (Fig. 8).

The largest fractionation factors are consistently reported for gaseous $\mathrm{N}$ losses (Bedard-Haughn et al., 2003; Robinson, 2001) so it is likely that changes in $\mathrm{N}_{2}, \mathrm{~N}_{2} \mathrm{O}$, NO, and $\mathrm{NH}_{3}$ losses account for the ${ }^{15} \mathrm{~N}$ enrichment in paddy soils. Nitrification- and denitrification- induced losses of $\mathrm{N}_{2}, \mathrm{~N}_{2} \mathrm{O}$, and $\mathrm{NO}$ were expected to increase under unsaturated soils typical for GCRPS cultivation as compared to continuous flooding of paddy soils that has also been documented in earlier studies (Kreye et al., 2007; Yao et al., 2014). Therefore, we can rule out both fertilizer effects and changes in denitrification losses as significant factors explaining lower $\delta^{15} \mathrm{~N}$ in GCRPS soils. The ${ }^{15} \mathrm{~N}$ enrichment in paddy soils and increased soil $\mathrm{N}$ stocks under GCRPS are therefore more likely related to ammonia volatilization following fertilizer application. Ammonia loss from urea fertilization in paddy rice fields can be very high with emission factors ranging from $9-40 \%$ of applied N (Xu et al., 2013). Covering the soil with a plastic film immediately after fertilizer application (Zhuang and Wang, 2010) or manure deposits (Webb et al., 2013) greatly reduces $\mathrm{NH}_{3}$ volatilization losses. Therefore, we expect that the greater soil $\mathrm{N}$ stocks in GCRPS fields were associated with decreased $\mathrm{NH}_{3}$ volatilization.

\section{Conclusion}

We demonstrate for the first time, across a wide range of spatially representative paired sites under real farming conditions, that GCRPS significantly increased soil organic C and total $\mathrm{N}$ stocks under varying edaphic conditions. GCRPS also increased above- and belowground root biomass in all soil layers down to $40 \mathrm{~cm}$ depth. This indicates that GCRPS is a stable and sustainable technique that maintains key soil functions, while increasing rice yield and expanding the cultivation of a valuable crop into regions where it has been hampered by low seasonal temperatures and/or a lack of irrigation water. However, the use of plastic sheets as cover material remains an obstacle because plastic residues often remain in the field and pollute the environment. Biologically degradable films may be a suitable solution to overcome this problem, and supplying such films with micronutrients may allow a more effective and integrated nutrient management that could further boost grain yields.

\section{The Supplement related to this article is available online at doi:10.5194/bg-12-4831-2015-supplement.}

Author contributions. M. Liu and M. Dannenmann contributed equally to this work. S. Lin and K. Butterbach-Bahl designed the experiments. M. Liu, S. Lin, M. Dannenmann, S. Sippel, Z. Yao, and K. Butterbach-Bahl conducted the regional field sampling. M. Liu performed the lab analysis and statistical analysis. G. Yan and G. Saiz performed the incubation and fractionation experiment. Y. Tao and Y. Zhang carried out the field experiment and were in charge of the root biomass. M. Liu, S. Lin, M. Dannenmann, G. Saiz, K. Butterbach-Bahl, and D. E. Pelster wrote the manuscript. All authors commented and revised the manuscript.

Acknowledgements. This work was supported by the National Natural Science Foundation of China (NSFC 41371286, 51139006), and especially by the Sino-German Centre for Science Promotion (GZ667). K. Butterbach-Bahl and D. E. Pelster were partly funded by the Climate Change Agriculture and Food Security (CCAFS) program of CGIAR institutes. We would like to thank the Agriculture Department of Shiyan for providing working facilities and organization of soil and plant sampling.

Edited by: Y. Kuzyakov

\section{References}

Amundson, R.: The carbon budget in soils, Annu. Rev. Earth Pl. Sc., 29, 535-562, 2001.

Bedard-Haughn, A., van Groeningen, J. W., and van Kessel, C.: Tracing ${ }^{15} \mathrm{~N}$ through landscapes: potential uses and precautions, J. Hydrol., 272, 175-190, 2003.

Blake, G. R. and Hartge, K. H.: Bulk density, in: Methods of Soil Analysis. Part 1. Physical and Mineralogical Methods, edited by: Arnold, K., Madison, Wisconsin, American society of agronomy Inc, 363-375, 1986.

Bouman, B. A. M.: A conceptual framework for the improvement of crop water productivity at different spatial scales, Agr. Syst., 93, 43-60, 2007.

Bronson, K. F., Cassman, K. G., Wassmann, R., Olk, D., van Noordwijk, M., and Garrity, D. P.: Soil carbon dynamics in different cropping systems in principal Ecoregions of Asia, in: Management of Carbon Sequestration in Soil, edited by: Lal, R., Kimble, J. M., Follett, R. F., and Stewart, Boca Raton, CRC Press Inc, 35-57, 1997.

Cassman, K. G., De Datta, S. K., Olk, D. C., Alcantara, J., Samson, M., Descalsota, J., and Dizon, M.: Yield decline and the nitrogen economy of long-term experiments on continuous, irrigated rice systems in the tropics, in: Soil Management: Experimental Basis for Sustainability and Environmental Quality, edited by: Lal, R., and Stewart, B. A., CRC Press, Boca Raton, 181-222, 1995.

Fan, J. B., Zhang, Y. L., Turner, D., Duan, Y. H., Wang, D. S., and Shen, Q. R.: Root physiological and morphological characteristics of two rice cultivars with different nitrogen-use effciency, Pedosphere, 20, 446-455, 2010. 
Fan, M. S., Lu, S. H., Jiang, R. F., Six, J., and Zhang, F. S.: Longterm non-flooded mulching cultivation influences rice productivity and soil organic carbon, Soil Use Manage., 28, 544-550, 2012.

FAO: Food Agricultural Organization UN, available at: http:// faostat.fao.org, last access: 12 July 2011.

Gao, Y. Z., Giese, M., Lin, S., Sattelmacher, B., Zhao, Y., and Brueck, H.: Belowground net primary productivity and biomass allocation of a grassland in Inner Mongolia is affected by grazing intensity, Plant Soil, 307, 41-50, 2008.

Gee, G. W. and Bauder, J. W.: Particle size analysis, in: Methods of Soil Analysis. Part 1. Physical and Mineralogical Methods, edited by: Klute, A., American Society of Agronomy, Madison, 383-411, 1986

Harris, D., Horwath, W. R., and Kessel, C.: Acid fumigation of soils to remove carbonates prior to total organic carbon or carbon-13 isotopic analysis, Soil Sci. Soc. Am. J., 65, 1853-1856, 2001.

IRRI: International Rice Research Institute, Los Banos, Laguna, Philippines, 2011.

Jenny, H.: Factors of Soil Formation: a System of Quantitative Pedology, New York, Dover, McGraw-Hill, 281 pp., 1941.

Ju, X. T., Xing, G. X., Chen, X. P., Zhang, S. L., Zhang, L. J., Liu, X. J., Cui, Z. L., Yin, B., Christie, P., Zhu, Z. L., and Zhang, F. S.: Reducing environmental risk by improving $\mathrm{N}$ management in intensive Chinese agricultural systems, P. Natl. Acad. Sci. USA, 9, 3041-3046, 2009.

Keeney, D. R. and Nelson, D. W.: Nitrogen in organic forms, in: Methods of Soil Analysis. Part 2. Chemical and Microbiological Properties, edited by: Page, A. L., Miller, R. H., and Keeney, D. R., Madison, Wisconsin, American society of agronomy Inc, 643-698, 1982.

Koch, O., Tscherko, D., and Kandeler, E.: Temperature sensitivity of microbial respiration, nitrogen mineralization, and potential soil enzyme activities in organic alpine soils, Global Biogeochem. Cy., 21, GB4017, doi:10.1029/2007GB002983, 2007.

Koegel-Knabner, I., Amelung, W., Cao, Z. H., Fiedler, S., Frenzel, P., Jahn, R., Kalbitz, K., Kölbl, A., and Schloter, M.: Biogeochemistry of paddy soils, Geoderma, 157, 1-14, 2010.

Kreye, C., Dittert, K., Zheng, X. H., Zhang, X., Lin, S., Tao, H. B., and Sattelmacher, B.: Fluxes of methane and nitrous oxide in water-saving rice production in north China, Nutr. Cycl. Agroecosys., 77, 293-304, 2007.

Kreye, C., Bouman, B. A. M., Castaneda, A. R., Lampayan, R. M., Faronilo, J. E., Lactaoen, A. T., and Fernandez, L.: Possible causes of yield failure in tropical aerobic rice, Field Crop. Res., 111, 197-206, 2009.

Leesawatwong, M., Jamjod, S., Kuo, J., Dell, B., and Rerkasem, B.: Nitrogen fertilizer increases seed protein and milling quality of rice, Cereal Chem., 82, 588-593, 2005.

Lehmann, J., Kinyangi, J., and Solomon, D.: Organic matter stabilization in soil microaggregates: implications from spatial heterogeneity of organic carbon contents and carbon forms, Biogeochemistry, 85, 45-57, 2007

Li, Y. S., Wu, L. H., Zhao, L. M., Lu, X. H., Fan, Q. L., and Zhang, F. S.: Influence of continuous plastic film mulching on yield, water use efficiency and soil properties of rice fields under nonflooding condition, Soil Till. Res., 93, 370-378, 2007.

Liang, Y. C., Hu, F., Yang, M. C., Zhu, X. L., Wang, G. P., and Wang, Y. L.: Mechanism of high yield and irrigation water use efficiency of rice in plastic film mulched dryland, Sci. Agr. Sin., 32, 26-32, 1999 (in Chinese with English abstract).

Liu, M. J., Lin, S., Dannemann, M., Tao, Y. Y., Saiz, G., Zuo, Q., Sippel, S., Wei, J. J., Cao, J., Cai, X. Z., and Butterbach-Bahl, K.: Do water-saving ground cover rice production systems increase grain yields at regional scales?, Field Crop. Res., 150, 19-28, 2013.

Liu, M. J., Liang, W. L., Qu, H., Zhi, G. Y., Chen, Q. X., Gong, Y. S., Butterbach-Bahl, K., and Lin, S.: Ground cover rice production systems are more adaptable in cold regions with high content of soil organic matter, Field Crop. Res., 164, 74-81, 2014

Liu, X. J., Wang, J. C., Lu, S. H., Zhang, F. S., Zeng, X. Z. Ai, Y. W., Peng, S. B., and Christie, P.: Effects of non-flooded mulching cultivation and nutrient management on crop growth, nutrient uptake and balances in rice-wheat cropping systems, Field Crops Res., 83, 297-311, 2003.

Mc Lean, E. O.: Soil pH and lime requirement, in Methods of Soil Analysis. Part 2. Chemical and Microbiological Properties, edited by: Page, A. L., Miller, R. H., and Keeney, D. R., Madison, Wisconsin, American society of agronomy Inc, 199-224, 1982.

Nacry, P., Bouguyon, E., and Gojon, A.: Nitrogen acquisition by roots: physiological and developmental mechanisms ensuring plant adaptation to a fluctuating resource, Plant Soil, 370, 1-29, 2013.

NASA and METI: Aster GDEM Aster Global digital elevation model (GDEM), Version 1.0, 2008.

Norvell, W. A.: Inorganic reaction of manganese in soils, in Manganese in Soils and Plants, edited by: Graham, R. D., Hannam, R. J., and Uren, N. C., Kluwer Academic, Dordrecht, the Netherlands, 37-58, 1988.

Pan, G. X., Li, L. Q., Wu, L. S., and Zhang, X. H.: Storage and sequestration potential of topsoil organic carbon in China's paddy soils, Glob. Change Biol., 10, 79-92, 2003.

Pan, G. X., Xu, X. W., Smith, P., Pan, W. N., and Lal, R.: An increase in topsoil SOC stock of China's croplands between 1985 and 2006 revealed by soil monitoring, Agr. Ecosyst. Environ., 136, 133-138, 2010.

Powlson, D. S., Gregory, P. J., Whalley, W. R., Quinton, J. N., Hopkins, D. W., Whitmore, A. P., Hirsch, P. R., and Goulding, K. W. T.: Soil management in relation to sustainable agriculture and ecosystem services, Food Policy, 36, S72-S87, 2011.

Qu, H., Tao, H. B., Tao, Y. Y., Liu, M. J., Shen, K. R., and Lin, S.: Ground cover rice production system increases yield and nitrogen recovery efficiency, Agron. J., 104, 1399-1407, 2012.

Rawls, W. J., Pachepsky, Y. A., Ritchie, J. C., Sobecki, T. M., and Bloodworth, H.: Effect of Soil Organic Carbon on Soil Water Retention, Geoderma, 116, 61-76, 2003.

Robinson, D.: $\delta^{15} \mathrm{~N}$ as an integrator of the nitrogen cycle, Trends Ecol. Evol., 16, 153-162, 2001.

Sahrawat, K. L.: Organic matter accumulation in submerged soils, Adv. Agron., 81, 169-201, 2004.

Saiz, G., Bird, M., and Domingues, T.: Variation in soil carbon stocks and their determinants across a precipitation gradient in West Africa, Glob. Change Biol., 18, 1670-1683, 2012.

Shen, K. R., Wang, X. C., and Luo, X. S.: Test and demonstration on wet-cultivation with film mulching of rice, Hubei Agricultural Sciences, 5, 18-22, 1997 (in Chinese with English abstract). 
Six, J., Bossuyt, H., Degryze, S., and Denef, K.: A history of research on the link between (micro) aggregates soil biota, and soil organic matter dynamics, Soil Till. Res., 79, 7-31, 2004.

Smit, B. and Cai, Y. L.: Climate change and agriculture in China, Global Environ. Chang., 6, 205-214, 1996.

Swift, R. S.: Sequestration of Carbon by Soil, Soil Sci., 166, 858871,2001

Tanji, K. K., Gao, S., Scardaci, S. C., and Chow, A. T.: Characterization redox status of paddy soils with incorporated rice straw, Geoderma, 114, 333-353, 2003.

Tao, H. B., Brueck, H., Dittert, K., Kreye, C., Lin, S., and Sattelmacher, B.: Growth and yield formation of rice (Oryza sativa L.) in the water-saving ground cover rice production system (GCRPS), Field Crop. Res., 95, 1-12, 2006.

Tao, H. B., Dittert, K., Zhang, L. M., Lin, S., Roemheld, V., and Sattelmacher, B.: Effects of soil water content on growth, tillering and manganese uptake of lowland rice grown in the watersaving ground cover rice production system (GCRPS), J. Plant Nutr. Soil Sc., 170, 7-13, 2007.

Tao, Y. Y., Zhang, Y. N., Jin, X. X., Saiz, G., Jing, R. Y., Guo, L., Liu, M. J., Shi, J. C., Zuo, Q., Tao, H. B., Butterbach-Bahl, K., Dittert, K., and Lin, S.: More rice with less water - evaluation of yield and resource use efficiency in ground cover rice production system with transplanting, Eur. J. Agron., 68, 13-21, 2015.

Tian, J., Pausch, J., Fan, M. S., Li, X. L., Tang, Q. Y., and Kuzyakov, Y.: Allocation and dynamics of assimilated carbon in rice-soil system depending on water management, Plant Soil, 363, 273285, 2013.

Tiessen, H., Cuevas, E., and Chacon, P.: The role of soil organic matter in sustaining soil fertility, Nature, 371, 783-785, 1994.

Thakur, A. K., Rath, S., Patil, D. U., and Kumar, A.: Effects on rice plant morphology and physiology of water and associated management practices of the system of rice intensification and their implications for crop performance, Paddy and Water Environ., 9, 13-24, 2011.

Uga, Y., Sugimoto, K., Ogawa, S., Rane, J., Ishitani, M., Hara, N., Kitomi, Y., Inukai, Y., Ono, K., Kanno, N., Inoue, H., Takehisa, H., Motoyama, R., Nagamura, Y., Wu, J. Z., Matsumoto, T., Takai, T., Okuno, K., and Yano, M.: Control of root system architecture by Deeper Rooting 1 increases rice yield under drought conditions, Nat. Genet., 45, 1097-1102, 2013.

Walthert, L., Graf, U., Kammer, A., Luster, J., Pezzotta, D., Zimmermann, S., and Hagedorn, F.: Determination of organic and inorganic carbon, $\delta^{13} \mathrm{C}$, and nitrogen in soils containing carbonates after acid fumigation with $\mathrm{HCl}$, J. Plant Nutr. Soil Sc., 173, 207-216, 2010.

Watts, C. W., Clark, L. J., Poulton, P. R., Powlson, D. S., and Whitemore, A. P.: The role of clay, organic $\mathrm{C}$ and long-term management on mouldboard plough draught measured on the broadbalk wheat experiment at Rothamsted, Soil Use Manage., 22, 334 341,2006
Webb, J., Sorensen, P., and Velthof, G.: An assessment of the variation of manure nitrogen efficiency throughout Europe and an appraisal of means to increase manure $\mathrm{N}$ efficiency, Adv. Agron., 119, 371-442, 2013.

Witt, C., Cassman, K. G., Olk, D. C., Biker, U., Liboon, S. P., Samson, M. I., and Ottow, J. C. G.: Crop rotation and residue management effects on carbon sequestration, nitrogen cycling and productivity of irrigated rice systems, Plant Soil, 225, 263-278, 2000.

Wopereis-Pura, M. M., Watanabe, H., Moreira, J., and Wopereis, M. C. S.: Effect of late nitrogen application on rice yield, grain quality and profitability in the Senegal river valley, Eur. J. Agron. 17, 191-198, 2002.

Wurster, C. M., Saiz, G., Calder, A., and Michael, I. B.: Recovery of organic matter from mineral-rich sediment and soils for stable isotope analyses using static dense media, Rapid Commun. Mass Sp., 24, 165-168, 2010.

Xiong, X., Grunwald, S., Myers, D. B., Ross, C. W., Harris, W. G., and Comerford, N. B.: Interaction effects of climate and land use/land cover change on soil organic carbon sequestration, Sci. Total Environ., 493, 974-982, 2014.

Xu, M. G., Li, D. C., Li, J. M., Quin, D. Z., Hosen, Y., Shen, H. P., Cong, R. H., and He, X. H.: Polyolefin-coated urea decreases ammonia volatilization in a double rice system of Southern China, Agron. J., 105, 277-284, 2013.

Yao, Z., Du, Y., Tao, Y., Zheng, X., Liu, C., Lin, S., and ButterbachBahl, K.: Water-saving ground cover rice production system reduces net greenhouse gas fluxes in an annual rice-based cropping system, Biogeosciences, 11, 6221-6236, doi:10.5194/bg11-6221-2014, 2014.

Yun, S. I., Lim, S. S., Lee, G. S., Lee, S. M., Kim, H. Y., Ro, H. M., and Choi, W. J.: Natural ${ }^{15} \mathrm{~N}$ abundance of paddy rice (Oryza sativa L.) grown with synthetic fertilizer, livestock manure compost, and hairy vetch, Biol. Fert. Soils, 47, 607-617, 2011.

Zhou, S. D., Herzfeld, T., Glauben, T., Zhang, Y. H., and Hu, B. C.: Factors affecting Chinese farmers' decisions to adopt a watersaving technology, Can. J. Agr. Econ., 56, 51-61, 2008.

Zhu, M., Xia, J., Zhang, Y. Z., and Yang, Z. T.: Analysis of Climate Changeable Character and Its Influence on Local Agriculture Production in Recent 50 Years in Shiyan, Acta Agriculturae Jangxi, 22, 149-151, 2010.

Zhuang, S. Y. and Wang, M. K.: Model estimation of ammonia volatilization from a paddy rice field after application of a surface film-forming material, J. Agr. Sci., 148, 95-100, 2010.

Zimmermann, M., Leifeld, J., Schmidt, M. W. I., Smith, P., and Fuhrer, J.: Measured soil organic matter fractions can be related to pools in the RothC model, Eur. J. Soil Sci., 58, 658-667, 2007. 